\title{
La responsabilidad social en las empresas de comunicación peruanas: La mirada de los stakeholders. Casos: ATV Televisión, Radio Capital y diario Perú 21
}

\author{
Julianna Ramírez Lozano, Mario Villacorta Calderón \\ (Universidad de Lima) ${ }^{1}$
}

Recibido: 28/11/2011

Aprobado: 18/1/2012

\begin{abstract}
Resumen: En el presente documento se hace una revisión conceptual del tema de la responsabilidad social, desde una mirada a diversos autores. Asimismo, se presenta un análisis acerca de la importancia e implicancia del significado de la responsabilidad social en las empresas de comunicación desde el conocimiento, la percepción y la opinión de sus stakeholders o grupos de interés. Para esto se ha tomado como referencia el caso de tres empresas peruanas de comunicación: ATV Televisión, Radio Capital y diario Perú 21.

Palabras clave: Responsabilidad social / empresa / stakeholders / medios de comunicación
\end{abstract}

\section{Social Responsibility in Peruvian media businesses: the stakeholders view. Case: ATV Television, Radio Capital and Perú 21}

Summary: This document explains in detail the conceptualization of social responsibility reviewing many authors' approaches. It also presents an analysis about the importance and implications of the meaning of social responsibility with the media taking count of the stakeholders' perceptions, opinions and knowledge. To achieve this, three local firms will be studied: ATV, Radio Capital and the newspaper Perú 21.

Keywords: Social responsibility business / stakeholders / media

1 El presente artículo es un resumen del documento final que se presentará al Instituto de Investigación Científica (IDIC) de la Universidad de Lima. En este trabajo también han participado, en calidad de practicantes, los alumnos Pierina García y Raúl Ruiz, de la misma universidad. 


\section{Introducción}

$\mathrm{L}$

a responsabilidad social empresarial es un concepto relativamente nuevo en el contexto peruano, pero cada vez es más conocido, pues implica que las empresas deciden emprender acciones que significan actuar de una manera socialmente responsable. En este sentido, la responsabilidad social significa realizar acciones como el cumplimiento de políticas, principios y códigos de ética que van más allá de la ley bajo la premisa del "ganar-ganar" de la empresa y de todos los stakeholders. Por esto, el concepto de responsabilidad social está vinculado directamente con la forma de gestión que tiene la organización, lo cual está en manos no solo de las personas que trabajan dentro de la empresa, sino principalmente en manos de los dueños o accionistas que dirigen la empresa.

El concepto de responsabilidad social empresarial se encuentra en constante evolución y, en el caso de los medios de comunicación o empresas de comunicación, el caso aún es poco estudiado. Por este motivo, planteamos la realización de un estudio en el que se busca entender de qué manera las empresas de comunicación pueden ser socialmente responsables. El estudio consistió en un monitoreo de los tres medios de comunicación y en un trabajo de campo orientado a conocer las percepciones de los stakeholders con respecto al tema. Para esto se tomó como referencia el caso de tres empresas: ATV noticias, Radio Capital y diario Peru 21.

En nuestro estudio comprendimos que la responsabilidad social en los medios de comunicación es un tema que se debe analizar desde dos ángulos. El primero, desde su rol social como medios productores de información, entretenimiento y educación, para lo cual se revisaron algunas reflexiones profesionales desde el mundo periodístico; y en segundo lugar, comprender su rol desde la empresa socialmente responsable, para lo cual revisamos algunos conceptos vinculados al mundo de la empresa en relación con la sociedad.

\section{La responsabilidad social de los medios de comunicación desde un marco conceptual}

El informe Hutchins (1947) se ha convertido en el punto de partida de cuanto análisis se realiza con respecto al tema de la responsabilidad social de los medios de comunicación. Este informe tomó como ejemplo el caso de la prensa escrita e inició el debate de la responsabilidad social de la prensa. El informe Hutchins ${ }^{2}$ destaca porque

2 Mientras que en los Estados Unidos la Comisión Hutchins se dedicaba a este tema, en Inglaterra, de manera paralela también se conformaba otro grupo denominado “Royal 
señala a los medios en su relación con otros dos actores: el público y el gobierno. Así, es una valiosa contribución a la teoría de la responsabilidad social de la prensa, que si bien hace referencia solo a la prensa escrita, no deja de ser válida y extensiva para todos los medios masivos de comunicación.

El informe plantea cinco funciones (Martin-Algarra y Rodríguez 2008) que la sociedad reclamaba a los medios de comunicación en esa época: a) ofrecer una narración verdadera, comprensiva e inteligible de acuerdo con los acontecimientos que suceden en la sociedad; b) ser un espacio de intercambio de comentarios y de crítica; c) ofrecer una imagen representativa de los grupos que constituyen la sociedad, de una manera democrática; d) presentar y clarificar las metas y valores de la sociedad; y e) ofrecer a la sociedad un completo acceso a la información.

El principal aporte del informe Hutchins consiste en entender que el rol de los medios de comunicación depende del ejercicio e interacción de tres actores: medios, gobierno y público, para lo cual se plantea recomendaciones $^{3}$ a cada uno de los tres actores. En este sentido, el informe nos ayuda a reconocer que el ejercicio de la prensa no solo depende de los periodistas, sino también de otros actores, como el gobierno, los dueños de los medios y la ciudadanía, en general. Hay dos temas particulares que queremos resaltar del documento: la ética del periodista y la ética de los propietarios de los medios de comunicación referente a los contenidos que se producen y emiten. Con respecto al primer punto podemos indicar que, algunas veces,

Commision of the Press". Este grupo de profesionales de la comunicación estaba integrado por la Unión Nacional de Periodistas de la Gran Bretaña. Ambos movimientos estaban preocupados por el mismo tema: el rol de la prensa.

3 Para el Gobierno: a) evite la intervención en los asuntos de los medios de comunicación; b) si hay que intervenir, esas intervenciones deberán tener un carácter positivo, evitando el monopolio y los abusos; c) recordar que la primera enmienda protege la libertad de expresión, pero no establece ningún privilegio para nadie; d) es preferible que se invite a la rectificación antes que entrar en un juicio por libelo. Para la prensa: a) la prensa debe asumir sus responsabilidades y actuar con conciencia; esto es preferible a que intervenga el Estado; b) la prensa tiene que reconocer el compromiso que tiene frente al público; c) la prensa debe ayudar a financiar actividades experimentales que faciliten la participación y, finalmente, fomenten el pluralismo. Para el público: a) la creación de instituciones sin afán de lucro que velen por que la prensa preste un servicio mejor en calidad y cantidad, b) la creación de centros de investigación y estudios en el ámbito de la comunicación; c) la creación de instituciones que informen sobre el desarrollo, la evolución y el estado de los medios de comunicación y sus influencias positivas y negativas en el público. 
los periodistas son censurados por los directivos de los medios de comunicación cuando se emite alguna información que puede afectar las relaciones con alguna empresa, institución o persona. Estas situaciones pueden ocasionar la renuncia del periodista al medio de comunicación. Con respecto al segundo punto, el informe Hutchins plantea la autorregulación de los propios medios como un mecanismo concreto por el cual un medio de comunicación puede ejercer plenamente su responsabilidad social. Para que exista un ejercicio de autorregulación, los medios deben desarrollar una serie de políticas internas para la producción, edición y emisión de contenidos. Este es un trabajo que, en el mejor de los casos, se traduce en los códigos de ética de los medios, aunque también hay códigos de ética de los propios periodistas o anunciantes, como es el caso de la Asociación Nacional de Anunciantes (ANDA) en el Perú.

\section{Informe Sean McBride}

Conocido también como el informe "Un solo mundo, voces múltiples", fue iniciado en 1977 y se presentó en 1980, por la Comisión Internacional para el estudio de los problemas de la comunicación de la Unesco. ${ }^{4}$

Este informe presenta un análisis acerca de la evolución del concepto de la comunicación y hace una revisión histórica de otras temáticas vinculadas con el ejercicio de los medios a partir del fenómeno de la comunicación. ${ }^{5}$ Este informe se detiene en el ejercicio de la responsabilidad social, pues presta importancia al marco legal, los roles y las responsabilidades de los profesionales de la comunicación y de los propietarios de los medios de comunicación. Asimismo, hace mención de las normas éticas y los códigos deontológicos que deben tener presentes los medios de comunicación al momento de emitir sus contenidos. El documento finaliza con una recapitulación de la comunicación desde una mirada global y haciendo recomendaciones para el futuro. En general, el informe McBride desarrolla un debate sobre la función social de la comunicación, desde dos visiones diferentes sobre los efectos de los medios en los públicos. La primera, que acepta y cree en la influencia y el poder de los medios de manera di-

4 La Comisión Internacional para el estudio de los problemas de la Comunicación de la Unesco fue presidida por Sean McBride y conformada por un grupo de 16 profesionales de la comunicación de diversos países y culturas del mundo. Entre los latinoamericanos destacan Gabriel García Márquez, de Colombia, y Juan Somavia, de Chile.

5 En los años anteriores a la realización de este informe, la comunicación era vista como un vehículo de expresión de la actividad social y de la civilización. 
recta en la población, visión que nos dice que los medios se atreven a recomendar al público lo que debe pensar y cómo debe comportarse. La segunda, más moderna, que intenta explicar que los medios de comunicación en sí no constituyen un gran agente de cambio social. El informe McBride explica algunos conceptos inherentes a los medios de comunicación, como los siguientes: la información, la socialización, la motivación, el debate y el diálogo, y la educación, el esparcimiento y la integración (McBride 1980: 37-38).

McBride hace referencia a los derechos y deberes de cada una de las partes que intervienen en los procesos de la comunicación. Dentro de estas interacciones se mencionan nociones como los derechos ciudadanos, la deontología del profesional de la comunicación, el rol del Estado, la cooperación internacional y otros. El informe señala que está en manos de los periodistas la función social de transmitir información, pero también de influir con ideas y puntos de vista en la opinión pública.

[...] el periodismo es una misión a la vez que es una profesión. Esto es especialmente importante porque la opi- nión publica depende más que nunca de quienes proporcionan noticias e informaciones objetivas, verídicas y no deformadas. Quienes acopian y difunden esas noticias y esas informaciones ocupan un lugar esencial en el funcionamiento de un sistema democrático (McBride 1980: 400).

En síntesis, el informe McBride es un segundo referente en la construcción de la teoría de la responsabilidad social de los medios de comunicación masivos, pues pone en tela de juicio los roles de cada una de las partes que intervienen en la producción y emisión de contenidos, en particular, el rol de los periodistas haciendo hincapié en el concepto de libertad de expresión y de la importancia de la elaboración de los códigos de ética.

\section{La responsabilidad social empresarial}

La responsabilidad social empresarial (RSE) es un nuevo concepto que en la década de 1990 tomó fuerza dentro del ámbito empresarial; sin embargo, sus orígenes se remontan a varios años atrás. ${ }^{6}$ Uno de los conceptos de responsabilidad social elaborado por los autores peruanos Matilde Schwalb y Óscar Malca7 (2005) dice:

6 Los orígenes de la RSE datan de 1890, cuando se llevó a cabo la exposición de la revolución industrial. A esta etapa se le considera como la 'empresarial'. La segunda etapa se inicia con la gran depresión de 1929, y la tercera etapa es la denominada del 'activismo social' (1960). Finalmente, estamos en la cuarta y por ahora última etapa denominada de 'conciencia social contemporánea', que se inició en 1980 (Schwalb y Malca 2005).

7 Schwalb y Malca son docentes de la Universidad del Pacífico, pionera en estudios de administración y gestión de empresas. 
La responsabilidad social es una filosofía, una actitud o forma de ver la vida que implica que tomemos en cuenta el efecto que nuestras acciones $\mathrm{y}$ decisiones tienen sobre el entorno físico y social. En otras palabras, ser socialmente responsable significa ser consciente del daño que nuestros actos pueden ocasionar a cualquier individuo o grupo social.

El ejercicio de la responsabilidad social empresarial atraviesa diversas responsabilidades que se conocen como triple balance: social, medioambiental y de ética y transparencia, que son cumplidas por las empresas de manera voluntaria. Ahora bien, debido a la necesidad que tienen las empresas de ser evaluadas con respecto a la puesta en marcha de su responsabilidad social, existen diversas instituciones a nivel mundial, que han desarrollado indicadores para medir la responsabilidad social de una empresa. Luego de un breve análisis de los diversos indicadores que utilizan cada una de estas instituciones podemos señalar que existen cinco áreas o indicadores: principios éticos y valores, condiciones y ambiente de trabajo, apoyo a la comunidad, protección del medio ambiente y márketing responsable. Así mismo, existen instrumentos y normas internacionales que sirven para medir el funcionamiento eficaz de la responsabilidad social de las empresas, como los informes de sistemas de gestión ambiental, ${ }^{8}$ el balance social, ${ }^{9}$ los reportes de sostenibilidad y otros.

La gestión de la responsabilidad social en las empresas es siempre en relación con sus stakeholders. Centrarse, organización de empresas autónomas, apolíticas y no lucrativas, ${ }^{10}$ indica que toda empresa tiene siete públicos -los más importantes- con los cuales se relaciona y tiene alguna obligación o responsabilidad. Esos públicos son: a) los accionistas: valores y transparencia, y márketing responsa-

8 Los sistemas de gestión ambiental o SGA funcionan a nivel mundial. Entre los más conocidos está la norma ISO 14001. Estos sistemas permiten a las empresas incorporar políticas de gestión ambiental. En el Perú, las compañías que exportan sus productos al exterior ya han implementado estos sistemas de gestión ambiental, como es el caso de las empresas Alicorp, Backus, Yanacocha, Antamina, Senati, etcétera.

9 El balance social es conocido actualmente como el sistema de evaluación por excelencia de la RSE. Este documento ha tenido una evolución; en sus inicios, en la década de 1970, se llamaba 'auditoría social'. En la de 1980 se llamó ‘balance social', y en la década de 1990 aparecieron los denominados 'informes sociales y medioambientales'. Los más recientes, es decir los del siglo XXI, se conocen como 'informes de sostenibilidad' o 'informes de gobierno corporativo'. Mayor detalle al respecto se puede encontrar en ACCID 2007: 61.

10 Esta organización busca generar una actitud de cambio en las empresas que operan en Guatemala, de todo sector y tamaño, para que adopten conscientemente prácticas de RSE. 
ble (principios éticos y valores); b) los trabajadores o colaboradores: actores internos (condiciones y ambiente de trabajo); c) los proveedores y la cadena productiva (márketing responsable); d) los consumidores, los clientes y los usuarios (márketing responsable); e) el medioambiente: interno y externo (protección del medio ambiente); f) la comunidad: del entorno de la empresa y de la sociedad (apoyo a la comunidad); g) y el Estado: las políticas públicas (apoyo a la comunidad).

En conclusión, la responsabilidad social es un compromiso voluntario y ético-moral que asume una empresa, la cual implica un comportamiento con determinadas conductas, acciones y políticas que cada empresa va desarrollando. Sabemos también que la aceptación de una empresa a una política de responsabilidad social significa el ingreso de la empresa a mayores oportunidades en el mercado. Sin duda, la responsabilidad social es un ejercicio en el que cada empresa va construyendo su propio modelo de acuerdo con sus características, tiempos y necesidades.

\section{La responsabilidad social desde la mirada de los stakeholders: ATV Noticias, ${ }^{11}$ Radio Capital ${ }^{12}$ y diario Peru $21^{13}$}

\section{Metodología del estudio}

El estudio se basó en una revisión de libros, revistas y artículos referentes al tema. Además, se revisaron documentos relacionados con la gestión de la RS

11 ATV: Andina de Radiodifusión S.A.C fue fundada el 18 de abril de 1983. A fines de la década de 1980 logró consolidarse gracias a programas periodísticos como Uno más uno y Fuego cruzado. También en esta época realizó sus primeras producciones dramáticas. Sin embargo, a fines de la década de 1990, la empresa entró en crisis debido a que su dueño, Julio Vera Abad, y el publicista Daniel Borobio, fueron vinculados con la mafia fujimontesinista. La recuperación institucional se inició en el año 2001, con un ordenamiento económico que, según sus directivos, ha permitido sanear las deudas. Luego de varios años de utilizar enlatados como principal insumo en su programación, en el 2011 apostó por la producción nacional en diversos géneros.

12 Radio Capital: En agosto del 2008, el Grupo RPP lanzó al aire la señal de Radio Capital 96.7, ocupando la frecuencia que durante años mantuvo Radio Corazón. Esta emisora nació con la premisa de convertirse en un espacio de participación del público, ofreciendo la posibilidad de opinar sobre los diversos temas que tocan sus conductores en los programas. Como estrategia de márketing, la emisora decidió contratar a reconocidos periodistas como Rosa María Palacios, Magaly Medina, Phillip Butters, entre otros.

13 Diario Perú 21: Fue lanzado en el 2002 por la Empresa Editora El Comercio. La propuesta de este nuevo medio de comunicación buscaba fusionar un diseño llamativo con una cobertura informativa variada. El primer director de Perú 21 fue Augusto Álvarez Rodrich, 
en los medios, como la Ley 28278 o Ley de Radio y Televisión, del 2004, en vigencia. Del mismo modo, se tomaron en cuenta documentos como el Código de Ética de la Sociedad Nacional de Radio y Televisión (SRNTV) y de la ANDA, el Pacto de Autorregulación de la SNRTV y el Pacto Mundial, la norma ISO 26000, la Iniciativa de Reporte Global (GRI, por sus siglas en inglés) y el Ethos Perú 2021 de Responsabilidad Social Empresarial.

Un segundo paso de la investigación consistió en el monitoreo en tres momentos diferentes, durante varias semanas y siguiendo diversas varia- bles elaboradas sobre la base de los documentos antes señalados. Finalmente, se desarrolló un trabajo de campo que consistió en la realización de tres grupos focales a periodistas de los tres medios de comunicación investigados, tres grupos focales a consumidores de los tres medios y 37 entrevistas en profundidad a representantes de los diversos stakeholders de los medios investigados.

\section{Mapeo de Stakeholders}

Antes de citar los puntos de vista de cada grupo de stakeholders investigados, procederemos a mostrar el mapeo

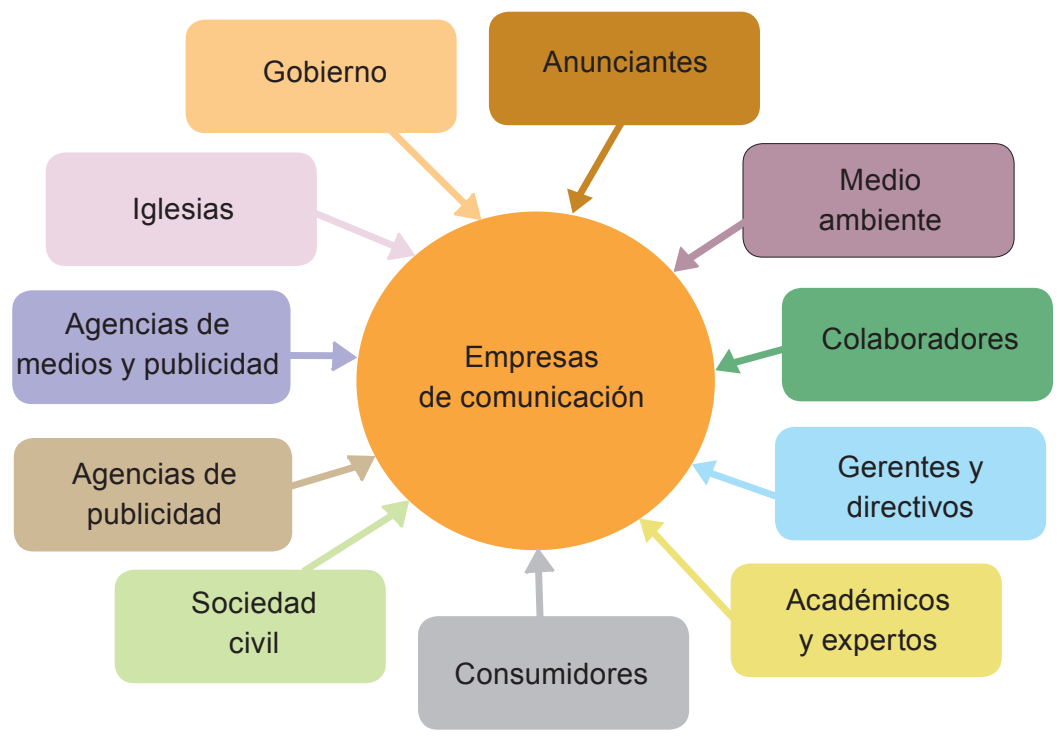

Elaboración propia.

quien se encargó de la publicación hasta fines del año 2008. Su salida se produjo en medio de un escándalo debido a los informes que preparó el diario acerca de los denominados "petroaudios". El cargo de director lo ocupa actualmente Fritz Du Bois. 
de stakeholders para una empresa de comunicación, tomando como referencia el caso peruano.

Es preciso indicar que, con excepción de los expertos y de los directivos de los medios, los otros stakeholders investigados no identificaron a los colaboradores como uno de los públicos más importantes. Pero la mayoría sí reconoció al público como el único o principal stakeholder de los medios de comunicación.

Expertos en el tema, como Lillian Zapata, comunicadora social y directora de la revista Imagen y Comunicación, hicieron mención de los siete grupos de interés de las empresas y señalaron la importancia de comenzar el trabajo internamente, para luego proyectar hacia el exterior una imagen de responsabilidad:

Antes que una empresa diga que es socialmente responsable con sus públicos externos, tiene que ser socialmente responsable por dentro, y eso significa aplicar los valores, cuidar a mi cliente interno, ser puntual en la planilla, respetar sus derechos. A partir de ahí podremos decir que somos socialmente responsables.

Paul Remy, secretario técnico del ISO 26000 Perú, también recalcó la importancia de la responsabilidad social con el público interno:

Va más allá de ofrecerle un sueldo alto a los empleados, hay que ofrecerles reconocimiento, comprensión y un sentimiento de involucramiento con la empresa para la que labora.

\section{Reflexiones de los stakeholders sobre la responsabilidad social en las empresas de comunicación} a) Los periodistas o colaboradores del
medio

Los periodistas de ATV relacionaron el concepto con el de ayuda social. En torno a la responsabilidad social de los periodistas, consideraron como punto de partida los valores y principios que tiene cada periodista, pero aseguraron que también hay que adecuarse a ciertos lineamientos y parámetros del medio de comunicación donde uno trabaja. Reflexionaron sobre lo importante que es no colocar escenas que muestren sangre o muertos, pues ellos lo entienden como una manera fácil de hacer rating.

Para los periodistas de Perú 21, el concepto de responsabilidad social está relacionado con el trabajo periodístico. En su mayoría, los participantes dijeron: "desde el momento que informamos ya estamos haciendo responsabilidad social". Además, explicaron que parte de la responsabilidad social de los periodistas es hacer bien su trabajo como, por ejemplo, contrastar las fuentes. Otros distinguieron la importancia de la calidad ética de los periodistas: "Si hay algo de lo que nos cuidamos en los procesos de selección... lo más importante es que haya personas que trabajen 
con honestidad, que no se presten a ser traficantes de la información...".

Por su parte, los periodistas de Radio Capital indicaron que la responsabilidad social parte del trabajo individual de cada periodista. Por ejemplo, señalaron la importancia de trabajar diversas acciones en beneficio de otros; citaron el caso de la campaña de reciclaje de papel que promovió un grupo de colaboradores del medio, la que fue adoptada por la gerencia de la emisora. Asimismo, los periodistas resaltaron la importancia de levantar temas de interés social; en este sentido, reconocieron la utilidad de campañas informativas sobre el transporte, la prohibición de comprar productos pirotécnicos, la cultura financiera, la seguridad ciudadana, entre otros.

Un dato que resulta destacable es el escaso interés que demostraron los periodistas con respecto al conocimiento de los marcos legales que regulan las empresas en las que trabajan. Por ejemplo, si bien es cierto que todos los entrevistados se mostraron a favor de la autorregulación por encima de una intervención del Estado, ninguno manifestó conocer los alcances del Pacto de Autorregulación de la Sociedad Nacional de Radio y Televisión, indicando que como periodistas o productores "no deben saber todo". Además, algunos señalaron que la responsabilidad de manejar esos temas recae en "la gente de arriba", haciendo referencia a los jefes o gerentes.

Con respecto al tema anterior, los periodistas manifestaron que para ellos es más efectiva la reunión de equipo que tienen todas las mañanas, en la cual se discuten los contenidos que se ofrecerán al público en cada programa. Otro documento que los periodistas admiten como importante, pero que a su vez no conocen, es la Ley de Radio y Televisión 28278, promulgada el 2004. Acerca de los códigos de ética desarrollados por la SNRTV o la ANDA, los entrevistados mostraron su desconocimiento acerca del contenido a pesar de estar al tanto de las consecuencias del Código de Ética.

b) Los consumidores: Oyentes, televidentes o lectores frecuentes

En general, las personas entrevistadas no tenían claro el concepto de responsabilidad en los medios, pues para algunos podía significar acciones filantrópicas que realizan las empresas en torno a la sociedad, mientras que otros señalaron que la responsabilidad social de los medios se debe entender como la promoción de valores y "cosas positivas" que el medio ofrece a su público mediante la información. Otro grupo entendía la responsabilidad social de los medios como "la manera de orientar o transmitir 
algo positivo a la sociedad". Un comentario fue acompañado de otro como: "los medios deben preocuparse por el impacto de cómo construyen el imaginario popular". Estas frases, sin duda, permitieron comentar sobre la cantidad y calidad de información que difunden los medios, así como la trascendencia de dicho material en la sociedad. Una crítica muy fuerte que se dio es la referida a la publicación de noticias sobre muertes y violaciones que suelen tener mayor cobertura en los espacios informativos.

Sin embargo, los participantes reconocieron también acciones concretas que los medios de comunicación desarrollan y que se pueden considerar como socialmente responsables, como las campañas relacionadas con los servicios a la comunidad en asuntos relativos a la educación vial o de prohibición de venta de alcohol a menores de edad, entre otros. En general, consideran que los medios también pueden cumplir una función educativa.

\section{c) Los directivos de los medios}

Se logró conversar con los tres gerentes/directores de los medios estudiados. Marcelo Cúneo, gerente general del Grupo ATV, destacó que la responsabilidad social que se ejerce en el canal se realiza desde el punto de vista empresarial. Cúneo considera que la relación más importante de la empresa es la que mantiene con su público interno; en este punto resaltó el cumplimiento de pagos y beneficios sociales a sus trabajadores. Además, consideró que como política de responsabilidad social, su canal está orientado a la integración del país.

En Radio Capital, Jesús Miguel Calderón, director de informaciones del Grupo RPP y ex gerente de Radio Capital, afirmó que las acciones y temáticas de responsabilidad social planteadas por la empresa, en primer lugar, son transmitidas a miembros de la emisora para que luego puedan reflejar ese pensamiento a los oyentes durante la conducción de los diversos programas. Calderón señaló que en Radio Capital se establece un cronograma de acciones que cada programa está obligado a cumplir y que va más allá de las campañas sociales, abarcando incluso los contenidos periodísticos.

El director del diario Perú 21, Fritz du Bois, considera que los medios de comunicación han desarrollado acciones de responsabilidad desde hace muchos años, presentando temas que son de interés para la comunidad. El director señaló que los temas que se plasman en las ediciones de Perú 21 no se plantean únicamente en función de la venta de diarios o de publicidad, sino del aporte a la sociedad, lo que los hace socialmente responsables. 
Con respecto a los códigos de ética, Cúneo señaló que ahora se cuidan los contenidos, indicando que ATV es una de las empresas impulsoras de los esquemas de autorregulación a lo largo de estos últimos años, que incluye el establecimiento de mecanismos para evitar la entrega de contenidos que puedan resultar ofensivos a los televidentes, para lo cual se ha designado a una persona que revise los contenidos periodísticos para garantizar que estén dentro de los lineamientos del canal; asimismo, que esté atenta a las quejas y reclamos que reciba la empresa. En el caso de Radio Capital, Jesús Miguel Calderón aseguró conocer los códigos y señaló que han sido muy importantes para que el Grupo RPP desarrolle su propio documento de código de ética que, a la fecha, se encuentra en plena difusión interna. En tanto, en el diario Perú 21, Du Bois comentó que se mantienen los llamados "principios rectores" del Grupo El Comercio.

d) La sociedad civil

$\mathrm{Al}$ igual que los grupos de interés anteriores, en este caso también se encontraron respuestas variadas con respecto al rol social que cumplen los medios de comunicación en el país. Para Daniel Chapell, representante del Comité de Radio, la responsabilidad social de un medio de comunicación comienza con la elección de las personas que tra- bajan en una empresa. Afirmó que la primera responsabilidad es velar por la calidad moral de los colaboradores, pues este concepto debe "respirarse dentro de la compañía como parte de su cultura".

Para Manuel Saavedra, director de la Compañía Peruana de Investigación de Mercado (CPI), la responsabilidad social de un medio de comunicación incluye la "formación de valores, por ejemplo, divulgar información que realmente tienda a reforzar los valores de la familia, campañas de prevención social, campañas de prevención del consumo de drogas, campañas a favor de la lucha contra la delincuencia". En tanto, Santiago Carpio, de Concortv, se centró en los contenidos que ofrecen los medios y consideró que la información debe cumplir con dos requisitos: "Ser lo más fidedigna posible y ser trascendente"; por esto, indicó, los medios deben ofrecer al público "otras facetas de la realidad para mejorar el entorno y la calidad de vida".

Víctor Urqueaga, director de Prensa de la Agencia de Relaciones Públicas de Corporación Pro, tuvo comentarios similares a los de Carpio, indicando que medios como Radio Capital tienen una estrategia de responsabilidad social dirigida a informar sobre "el éxito de emprendedores sociales que obtienen grandes logros". Por su parte, Roberto Mejía, presidente de la 
Asociación Nacional de Periodistas (ANP), resaltó el trabajo de Radio Capital como un medio que permite a sus consumidores dejar de ser solo radioescuchas.

Miriam Larco, secretaria ejecutiva de Concortv, considera que el rol social de los medios de comunicación debe comenzar por evaluar las maneras como los periodistas obtienen la información y el tipo de imágenes que incluyen en sus reportajes. De la misma manera, Alizath Espino, secretaria general de la Comisión Episcopal de Comunicación Social (Conamcos), lamentó haber constatado, después de realizar un estudio, que el 90 por ciento de las noticias presentadas por algunas empresas estén referidas a "violaciones, matanzas, muertes... y esas noticias enferman a las personas", afirmó.

Giovanni Romero, coordinador de Fortalecimiento Comunitario LGTB del Movimiento Homosexual de Lima (MHOL), comentó que existen ciertas prácticas utilizadas por determinados periodistas con el objetivo de darle mayor sensacionalismo a su información. Sobre este punto admitió ser uno de los afectados.

Con respecto a la utilidad de los códigos de ética que están relacionados con los medios de comunicación, varios entrevistados mostraron una postura más crítica, como Roberto Mejía, quien reconoció que algunos de sus colegas realizan su trabajo sin respetar las normas éticas y usan el periodismo como un medio de presión que brinda o calla información de acuerdo con lo que más le conviene.

En lo referente al Código de Ética de la ANDA y su Semáforo Ético, el director ejecutivo de esta asociación, Rodolfo León, aclaró que no constituye un mecanismo de regulación, pues tampoco es vinculante para sus propios asociados. Sin embargo, la opinión generalizada de los otros entrevistados fue que el Semáforo Ético sí constituye un mecanismo de autorregulación. Carlos Ruiz señaló que algunos anunciantes siguen a rajatabla este semáforo, pero también afirmó que la decisión final de dónde publicitar depende del mismo anunciante, que puede pasar por alto las recomendaciones hechas por la ANDA o la agencia.

e) Los especialistas y estudiosos de los medios de comunicación

Los entrevistados coincidieron en que los medios de comunicación trabajan con un producto llamado "información", el cual es una variable que los diferencia de otras empresas. Al respecto, María Teresa Quiroz, presidenta del Comité de Ética del Consejo de la Prensa Peruana, indicó que "un medio de comunicación trabaja básicamente con la introducción de mensajes de naturaleza distinta, ya sea informativa o de entretenimiento, que 
tiene que resguardar los derechos básicos y humanos del público al que se dirigen". A este comentario se suma el del profesor David Hernández, de la Universidad de Antioquia, quien nos recordó que todos los medios deben tener periodistas con conciencia y que entiendan que su profesión tiene implicaciones sociales muy amplias.

Por su parte, Rosa María Alfaro, directora de la ONG Calandria, considera que los medios de comunicación deberían aprovechar su posición no solo para comunicar, sino también para colaborar con la comunicación entre diversos grupos sociales: "En un país en el que la ciudadanía es muy pobre en sí misma, es más importante ver antes si lo que les doy a los peruanos los ayuda a ubicarse en el país, a hacer cosas por su país, a presionar con cambios, a establecer diálogos".

Otros entrevistados prefirieron destacar acciones y políticas de responsabilidad social ejecutadas por medios ajenos al estudio. Por ejemplo, Lillian Zapata consideró interesante la iniciativa de RPP de entregar el premio "Integración", y Rosario Sheen, ex jefa de Responsabilidad Social de la Universidad de Lima, destacó el trabajo de El Comercio al realizar las audiencias ciudadanas, por fomentar la participación de la sociedad y darle la posibilidad de expresar sus preocupaciones en torno a problemas gubernamentales.

\section{f) El Gobierno}

En este punto es importante reflexionar sobre el rol que ocupa el gobierno en relación con los medios de comunicación. Sobre este punto, la gran mayoría de los entrevistados manifestaron estar de acuerdo en que los medios deben autorregularse, al respecto, Baltazar Caravedo, director del Centro de Liderazgo de la Universidad del Pacífico y Presidente del Instituto SASE, señaló:

La idea de la autorregulación es crear más conciencia. Si tenemos directivos que toman las decisiones, que son conscientes de todas las implicancias que tiene este nuevo patrón de vínculos, esta nueva ética, entonces, los medios no requerirían ser regulados... Pero el conflicto que se establece es saber hasta dónde llegan mis derechos y hasta dónde mis obligaciones, hasta dónde llegan los derechos y las obligaciones de los demás.

Por su parte, Jesús Munive, director general de Control y Supervisión de Comunicaciones del Ministerio de Transportes y Comunicaciones, comentó que el Ministerio de Transportes y Comunicaciones no centra su actividad en controlar las opiniones e informaciones vertidas en los diferentes programas, pero indicó que la ley considera ciertas restricciones que son definidas por el propio medio a través de su Código de Ética.

Munive también señaló que la ley indica los mecanismos que 
pueden seguir los consumidores que no están de acuerdo con los contenidos de los medios de comunicación. Según explicó, la primera opción es que se desarrolle un procedimiento de queja ante la propia radio, para que esta, por autorregulación, pida disculpas y se comprometa a evitar que se repita dicha situación, con lo cual terminaría el conflicto. La segunda opción es presentar una denuncia ante el Ministerio si es que el medio no ha resuelto la queja presentada previamente. Es decir, las formas como una persona puede presentar una queja ante un medio de comunicación deben estar establecidas en el código de ética elaborado por cada una de dichas empresas. En el caso peruano, la mayoría de los canales y emisoras siguen el códi- go que ha elaborado la SNRTV, el cual, en opinión de Munive, debe ser mejorado.

h) El medio ambiente

Ninguno de los entrevistados reconoció el medioambiente como uno de los stakeholders con los que los medios de comunicación establecen una relación.

\section{Indicadores para el análisis de la responsabilidad social en los medios de comunicación}

Uno de los aportes de esta investigación ha sido la elaboración de algunos indicadores que ayuden a identificar la gestión de la responsabilidad social de las empresas de comunicación. Luego de nuestra investigación encontramos

\section{Indicadores}

\section{Contenidos: informativo, de entretenimiento, edu- cativo y de publicidad}

\section{Variedad de noticias}

Búsqueda de la veracidad

Manejo de temas de interés ciudadano

Diferencia entre información y opinión

Participación del público

Buen manejo de la publicidad
Políticas empresariales y de responsabilidad social

Transparencia y buen gobierno corporativo.

Respeto al marco legal

Involucramiento de

los colaboradores y buen

manejo de la cultura corporativa

Respeto a las diferencias, contra la discriminación y en favor de la inclusión
Campañas de RS

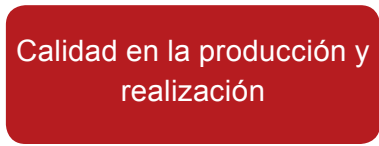

Temáticas en relación con principios y valores del medio

Vinculación con políticas empresariales

Alianzas estratégicas con stakeholders 
tres grandes temas desde los cuales se puede evaluar la gestión de responsabilidad social en los medios: a) el análisis de los contenidos informativos, de entretenimiento y publicitarios; b) las políticas empresariales de responsabilidad social; y 3) la realización de campañas de responsabilidad social empresarial. Cada uno de estos temas tiene diversas variables que deben tomarse en cuenta para la realización de un análisis de responsabilidad social en los medios de comunicación.

\section{Conclusiones del estudio}

- El concepto de responsabilidad social en las empresas de comunicación peruanas aún es un concepto poco estudiado pero sí discutido desde la sociedad civil. Sin embargo, los directivos de los tres medios investigados han respondido con claridad acerca del tema, identificando que sus acciones están encaminadas desde un enfoque de responsabilidad social empresarial.

- En opinión de todos los entrevistados, la responsabilidad social en los medios de comunicación comerciales está relacionada con la forma, los valores y el cuidado ético por los cuales los medios ponen al aire sus contenidos y, sobre todo, se destaca el rol de los periodistas.

- Aún está pendiente trabajar en el reconocimiento de los stakeholders de los medios de comunicación, pues la mayoría de los entrevistados solo reconoce como único stakeholder al público.

- La mayoría de los stakeholders de los medios tienen opiniones diversas. Algunos piensan que los medios de comunicación en nuestro país no realizan una acción de responsabilidad social, mientras otros reconocen que aún tienen mucho por desarrollar, pues los medios deben cumplir un rol más protagónico en la sociedad hasta llegar a convertirse en los promotores de valores sociales y de formación de ciudadanía, lo cual generará un reconocimiento de parte de la población.

- Para los periodistas, la responsabilidad social en los medios se sustenta en un trabajo periodístico basado en la veracidad, el respeto a los derechos humanos y la producción de contenidos de interés social para los consumidores. Los periodistas investigados sienten que su trabajo es socialmente responsable, pues ellos buscan ser objetivos y siempre colaboran con sus públicos mediante el tratamiento de temas sociales que resultan prácticos para sus consumidores, o mediante la puesta en marcha de diversas campañas en temas sociales.

- El mayor reconocimiento de los stakeholders acerca de la acción de responsabilidad social de los medios es mediante la elaboración de contenidos que aporten a la calidad 
de vida de los ciudadanos. Aquí se destacan programas de salud, consultorios médicos y ayuda en caso de emergencia. Por su parte, los consumidores frecuentes de los medios investigados reconocen que estos aportan a su calidad de vida. Sin embargo, también rechazan los contenidos con valores negativos para la sociedad, que no aportan nada positivo a pesar de la alta audiencia.

- Por otro lado, en opinión de algunos de los stakeholders, en determinados casos, los medios no siempre cumplen con el respeto a la ley o los códigos de ética, por lo cual en diversos casos deben rectificarse o pedir disculpas a las personas agredidas.

- Los medios de comunicación deben trabajar en la creación de alianzas con diversos sectores de la población, con el fin de canalizar el tratamiento de temas de interés social, lo cual se convierte en políticas y acciones de responsabilidad social de los propios medios de comunicación.

- No se ha registrado mayor conocimiento ni conciencia de que la adecuada gestión de la responsabilidad social en los medios de comunicación pueda afectar positivamente la cultura, la imagen y la reputación organizacional de la empresa de comunicación. Por esto, queda pendiente el trabajo de los medios con sus stakeholders. En un primer nivel, realizando un mapeo de los medios, y en segundo lugar, trabajando en la gestión de un desarrollo sostenible que tenga como punto de partida las buenas relaciones con los diversos stakeholders, en especial con los colaboradores o periodistas del medio.

\section{Bibliografía}

ACCID (2007). Responsabilidad social corporativa. Barcelona: Ediciones Gráficas Rey.

Fundación Nuevo Periodismo IbeROAMERICANO (2008). "La otra cara de la libertad". <http://www. fnpi.org/fileadmin/documentos/ Publicaciones/P_FNPI_RSE_La_ otra_cara_de_la_libertad.pdf $>$. [Consulta: abril del 2010].

Global Reporting Initiative (2006). Guía para la elaboración de memorias de sostenibilidad. <http:// w w w.observatorio-rse.org. es/Publicaciones/Guia.pdf $>$. [Consulta: abril del 2010].

Hutchins, Robert (1947). "Prólogo", en Commission on freedom of the press: $A$ free and responsible press. Chicago: University of Chicago Press.

Martin-Algarra, Manuel y Xosé RoDRíGuez (2008). "Medios y democracia: La teoría de la responsabilidad social". Revista de Comunicación. Vol. 7. Piura: Universidad de Piura, Facultad de Comunicación. 
Martínez, Juan Luis; Carbonell, Mcquall, Denis (1992). La acción de los María y Ana Agüero (2006). Los stakeholders y la acción social de la empresa. Madrid: Fundación Rafael el Pino/Marcial Pons/Ediciones Jurídicas y Sociales S. A.

McBride, Sean (1980). Un solo mundo, voces múltiples, comunicación e información en nuestro tiempo. París: Unesco. medios, los medios de comunicación y el interés público. Buenos Aires: Amorrortu editores.

Schwalb, Matilde y Óscar Malca (2005). Responsabilidad social: Fundamentos para la competitividad empresarial y desarrollo sostenible. Lima: Universidad del Pacífico. 
Anexo

Listado de personas entrevistadas

\begin{tabular}{|c|c|c|}
\hline Institución a la que pertenece & Cargo & Nombre \\
\hline $\begin{array}{l}\text { Asociación Nacional de } \\
\text { Anunciantes (ANDA) }\end{array}$ & Director ejecutivo & Roberto León \\
\hline $\begin{array}{l}\text { Asociación Nacional de } \\
\text { Periodistas (ANP) }\end{array}$ & Presidente & Roberto Mejía Alarcón \\
\hline ATV & Conductora de noticieros & Pamela Vértiz \\
\hline ATV & Conductora de noticieros & Pilar Higashi \\
\hline ATV & Gerente general & Marcelo Cúneo \\
\hline ATV & Jefe de Informaciones & Ricardo Correa \\
\hline ATV & Conductor Hola a Todos & Mathías Brivio \\
\hline Chirinos, Salinas y Cateriano & Director asociado & Pedro Salinas \\
\hline $\begin{array}{l}\text { Comisión Episcopal en } \\
\text { Comunicación Social } \\
\text { (Conamcos) }\end{array}$ & Secretaria ejecutiva & Alitzah Espino \\
\hline Comité de Radio & $\begin{array}{l}\text { Consultor principal del Comité de } \\
\text { Radio }\end{array}$ & Daniel Chapell \\
\hline Concortv & Secretaria técnica & Miriam Larco Sicheri \\
\hline Concortv & Presidente & Santiago Carpio Valdez \\
\hline Consejo de la Prensa Peruana & Directora ejecutiva & Kela León Amézaga \\
\hline Consejo de la Prensa Peruana & Presidenta del Tribunal de Ética & María Teresa Quiroz Velasco \\
\hline Corporación Pro & Director de Prensa & Víctor Urqueaga \\
\hline $\mathrm{CPI}$ & Gerente general & Manuel Saavedra \\
\hline Diario El Tiempo (Colombia) & Ombudsman & $\begin{array}{l}\text { Javier Darío Restrepo } \\
\text { (Colombia) }\end{array}$ \\
\hline Diario Perú 21 & Director & Fritz Du Bois \\
\hline Diario Perú 21 & Columnista & Santiago Pedraglio \\
\hline Diario Perú 21 & Editora de la sección ciudad & Esther Vargas \\
\hline $\begin{array}{l}\text { Instituto Prensa y Sociedad } \\
\text { (IPYS) }\end{array}$ & Jefatura de Prensa & Adriana León \\
\hline Lundú & Presidenta ejecutiva & Mónica Carrillo \\
\hline $\begin{array}{l}\text { Ministerio de Transportes y } \\
\text { Comunicaciones }\end{array}$ & $\begin{array}{l}\text { Director general de Control y } \\
\text { Supervisión de Comunicaciones }\end{array}$ & $\begin{array}{l}\text { Jesús Wilfredo Munive } \\
\text { Taquia }\end{array}$ \\
\hline $\begin{array}{l}\text { Movimiento Homosexual de } \\
\text { Lima (MOHL) }\end{array}$ & Secretario ejecutivo & Giovanni Romero \\
\hline
\end{tabular}

(continúa) 
(continuación)

\begin{tabular}{|l|l|l|}
\hline Institución a la que pertenece & \multicolumn{1}{|c|}{ Cargo } & Nombre \\
\hline ONG Calandria & Socia fundadora & Rosa María Alfaro \\
\hline Perú 2021 & Jefa de Comunicaciones & Diana Fernández \\
\hline Perú 2021 & $\begin{array}{l}\text { Directora de Gestión del } \\
\text { Conocimiento }\end{array}$ & Cecilia Rizo-Patrón \\
\hline Radio Capital & $\begin{array}{l}\text { Director de Informaciones (Grupo } \\
\text { RPP) }\end{array}$ & Jesús Miguel Calderón \\
\hline Radio Capital & Conductor & Jesús Veliz \\
\hline Radio Capital & Conductor & Augusto Álvarez Rodrich \\
\hline Revista Imagen y Comunicación & Directora & Lillian Zapata \\
\hline Revista Stakeholders & Director & Javier Arce Novoa \\
\hline Sase Consultores & Presidente & Baltazar Caravedo \\
\hline Starcom & Gerente general & Carlos Ruiz \\
\hline Universidad de Lima & Jefa de Responsabilidad Social & Rosario Sheen \\
\hline ISO 26000 & Secretario técnico ISO 26000 Perú & Paul Remy \\
\hline $\begin{array}{l}\text { Universidad de Antioquia } \\
\text { (Colombia) }\end{array}$ & $\begin{array}{l}\text { Vicerrectorado de la Universidad } \\
\text { de Antioquia }\end{array}$ & David Hernández \\
\hline
\end{tabular}

